\title{
基 \\ Caracterização de equinos competidores de Pega de Boi no Mato
}

[Characterizing horses competing in "Pega de Boi no Mato”]

"Artigo Científico/Scientific Article"

\author{
Diogo Luiz dos Santos Lima ${ }^{1}$, Juliano Martins Santiago ${ }^{1 *}$, Jorge Eduardo Cavalcante Lucena ${ }^{2}$, \\ Helyanna de Siqueira Pereira ${ }^{1}$, Anailza Cristina Guedes Sá Leite ${ }^{1}$, Estefani Gomes Silva ${ }^{1}$, Igor \\ Masterson de Farias ${ }^{1}$, Layanne Morgana Marçal Nunes ${ }^{1}$, Winicius Ferreira Moraes ${ }^{1}$, Daniel \\ Ânderson de Souza Melo ${ }^{1}$
}

\begin{abstract}
${ }^{1}$ Unidade Acadêmica de Serra Talhada, Universidade Federal Rural de Pernambuco, Serra Talhada-PE, Brasil.
${ }^{2}$ Departamento de Zootecnia, Universidade Federal do Agreste de Pernambuco, Garanhuns-PE, Brasil.

*Autor para correspondência/Corresponding author: E-mail: jmartinssantiago@yahoo.com.br
\end{abstract}

\begin{abstract}
Resumo
Objetivou-se com o trabalho caracterizar os equinos participantes de Pegas de Boi no Mato e verificar se esses animais permanecem com as características físicas do remanescente cavalo Nordestino, raça pioneira na lida com o gado no Sertão, ou se estão aproximando das dimensões corporais dos cavalos Quarto de Milha, raça exótica em ascensão no Nordeste brasileiro devido às Vaquejadas. Para tanto, foram utilizados 102 equinos participantes de Pegas de Boi no Mato. A primeira etapa do estudo consistiu em uma entrevista aos proprietários dos cavalos, com aplicação de questionário predefinido, para obter informações sobre os animais. $\mathrm{Na}$ segunda etapa foram obtidas 15 medidas lineares dos equinos e com elas calculados sete índices morfométricos. As medidas foram utilizadas para comparar dois grupos raciais, mestiços e animais sem raça definida, através do delineamento experimental inteiramente ao acaso composto pelos dois tratamentos (grupos raciais). Observou-se nas Pegas de Boi no Mato, predomínio de equinos machos castrados, na faixa etária entre 5 e 10 anos, de pelagens alazã, tordilha e castanha, cujas funções vão além das participações nas disputas. Os equinos mestiços apresentaram valores superiores aos animais sem raça definida em nove das 15 medidas lineares. Além disso, houve diferença entre os grupos raciais em cinco dos sete índices morfométricos. Concluiu-se que tanto os mestiços quanto os equinos sem raça definida participantes das Pegas de Boi no Mato possuem medidas e proporções corporais intermediárias entre o remanescente cavalo Nordestino e equinos Quarto de Milha de Vaquejada.
\end{abstract}

Palavras-chave: cavalo nordestino; quarto de milha; vaquejada.

\begin{abstract}
This study aimed to characterize the horses that take part in "Pega de Boi no Mato" - Cattle Capture in the Brush, in free translation - competitions and to verify whether those animals maintain the physical characteristics of the remaining Nordestino horse, a pioneer breed for cattle work in the "sertão" hinterland, or whether they are moving towards the body dimensions of the Quarter Horse, a rising exotic breed in the Brazilian Northeast region due to "vaquejada" contests. To that end, 102 horses participating in "Pega de Boi no Mato" were used. The first stage of the study consisted of an interview with the horse owners, using a predefined questionnaire, to obtain information on the animals. In the second step, 15 linear measurements were collected from the horses and used to calculate seven morphometric indices. The morphometric results were used to compare two breed groups, i.e., crossbred and horses of undefined breed, using a completely randomized experimental design comprising the two treatments (breed groups). A predominance of geldings between five and ten years old of chestnut, grey, and brown coats whose roles go beyond competing was observed in the "Pega de Boi no Mato" contests. The crossbred horses had higher values than those of undefined breed in nine of the 15 linear measures. In addition, a difference was found between the breed groups in five of the seven morphometric indices. It is concluded that both crossbred horses and those of undefined breed that compete in "Pega de Boi no Mato" have intermediate measurements and body proportions between those of the Nordestino breed and vaquejada Quarter Horse animals.
\end{abstract}

Keywords: Nordestino horse; quarter horse; "vaquejada". 


\section{Introdução}

A Pega de Boi no Mato consiste em uma atividade tradicional que simboliza o início da ocupação do Sertão Nordestino. Essa prática e a tradicional figura do vaqueiro fazem parte da cultura sertaneja, reforçando e reverberando a identidade e o cotidiano do homem do Sertão (Cavalus, 2018). Para capturar o bovino solto na Caatinga os vaqueiros enfrentam galhos, troncos, pedras, buracos, espinhos de Jurema e touceiras de Xique-Xique, demonstrando coragem e valentia. Os acidentes são frequentes, pois os cavalos alcançam velocidades próximas a $60 \mathrm{~km} / \mathrm{h}$ durante as perseguições (Menezes e Almeida, 2008). Segundo Pereira (2016), não há treinamento ou qualquer tipo de preparação prévia dos vaqueiros e seus cavalos, pois essa atividade remonta o estilo de vida, a trajetória social e o cotidiano no qual os vaqueiros estão inseridos, sendo a rotina no campo suficiente para que se aprimore a prática e saberes que lhes serão úteis nas competições.

Para adentrar a Caatinga fechada atrás do bovino, desviando dos obstáculos naturais, a montaria do vaqueiro deve ser ágil, compacta e resistente. Para isso, a seleção natural imposta aos equinos ibéricos introduzidos no Nordeste pelos colonizadores resultou em animais de pequeno porte, adaptados às altas temperaturas, baixa umidade e escassez de chuva que leva às restrições de água e alimento, dentre outras adversidades do bioma (Melo et al., 2013).

A partir desses animais já adaptados à Caatinga, em 13 de fevereiro de 1974 foi fundada a Associação Brasileira de Criadores do Cavalo Nordestino (ABCCN), visando manter o controle genealógico e fomento da raça (CCCCN, 1983). Todavia, as atividades dessa associação foram encerradas na década de 90 . Em termos de rebanho efetivo, a situação da raça é crítica, pois não existem mais núcleos de preservação e seleção, situação resultante principalmente do não funcionamento da ABCCN e da ausência de políticas prioritárias para conservação deste recurso genético (Melo et al., 2013).

Os cavalos adaptados ao Sertão Nordestino contribuíram para o desenvolvimento das atividades agropecuárias no interior dos estados, atuando na lida do gado, transporte de pessoas, cargas e tração leve. Por falta de conhecimento e valorização das características de resistência e rusticidade desses equinos, muitos criadores estão promovendo o cruzamento com cavalos Quarto de Milha, visando animais de maior porte, força e beleza. Porém, esses cruzamentos estão levando ao desaparecimento de características necessárias para sobrevivência no bioma Caatinga (Costa et al., 2001). Neste sentido, objetivou-se com o trabalho caracterizar os equinos competidores de Pegas de Boi no Mato e verificar se esses animais permanecem com as características físicas do remanescente cavalo Nordestino, ou se estão aproximando das dimensões e proporções corporais da raça Quarto de Milha.

\section{Material e Métodos}

$\mathrm{O}$ estudo foi desenvolvido por meio de visitas a propriedades rurais do Sertão do Pajeú e a disputas de Pegas de Boi no Mato realizadas no Sertão e Agreste Pernambucano, onde foram coletadas informações e medidas morfométricas de 102 equinos participantes de Pegas de Boi no Mato, sendo 55 sem raça definida e 47 mestiços.

A primeira etapa consistiu em uma entrevista aos proprietários dos equinos, utilizando formulário pré-definido, para obter informações sobre a cidade ou município onde o animal é criado, sexo, raça, idade, pelagem e funções exercidas pelo equino além da participação em Pegas de Boi no Mato.

Na segunda etapa foram obtidas 15 medidas lineares dos equinos, utilizando hipômetro e fita métrica com precisão de $0,01 \mathrm{~cm}$. No momento das mensurações, os animais foram posicionados em estação forçada. As medidas lineares foram realizadas de acordo com metodologia descrita por Santiago et al. (2016):

- Altura na cernelha: distância entre as extremidades livres do $5^{\circ}$ ou $6^{\circ}$ processo espinhoso das vértebras torácicas e o solo;

- Altura do dorso: distância entre a extremidade livre dos processos espinhosos da $12^{\mathrm{a}}$ e $13^{\mathrm{a}}$ vértebra torácica e o solo;

- Altura da garupa: distância entre o ponto mais alto da transição lombo-sacra e o solo;

- Altura do costado: distância entre os processos espinhosos da $12^{\mathrm{a}}$ e $13^{\mathrm{a}}$ vértebra torácica e o processo xifoide das esternébras;

- Comprimento da cabeça: distância entre a extremidade do focinho e a nuca;

- Comprimento do pescoço: distância entre a porção cranial da face lateral da asa do Atlas e a borda cranial do terço médio do músculo supra-espinhoso;

- Comprimento dorso-lombar: distância entre os processos espinhosos da $8^{\mathrm{a}}$ vértebra torácica e da $7^{\mathrm{a}}$ vértebra lombar; 
- Comprimento da garupa: distância entre a porção cranial da face lateral da tuberosidade ilíaca e a tuberosidade isquiática;

- Comprimento da espádua: distância entre a porção central da extremidade proximal da cartilagem escapular e o centro da articulação escápulo-umeral;

- Comprimento do corpo: distância entre a borda cranial da articulação escápulo-umeral e a tuberosidade isquiática;

- Largura da cabeça: distância entre as extremidades distais dos processos zigomáticofrontais ou supraorbitários direito e esquerdo;

- Largura do peito: distância entre os tubérculos maiores laterais dos úmeros direito e esquerdo;

- Largura da garupa: distância entre as proeminências mais laterais das tuberosidades ilíacas direita e esquerda;

- Perímetro torácico: a fita métrica circundou o tórax, fazendo contato com a extremidade livre do processo espinhoso da $11^{\text {a }}$ vértebra torácica e a região do $9^{\circ}$ espaço intercostal;

- Perímetro da canela: a fita circundou o terço médio do $3^{\circ}$ osso metacarpiano.

$\mathrm{Na}$ sequência, as medidas lineares foram utilizadas para calcular sete índices morfométricos, descritos e referendados por Oom e Ferreira (1987), Ribeiro (1989) e Torres e Jardim (1992):

- Peso calculado aproximado $=$ (perímetro torácico $)^{3}$ x $80(\mathrm{~kg})$;

- Vazio subesternal = altura na cernelha - altura do costado (m);

- Índice dáctilo-torácico (IDT) = perímetro da canela/perímetro torácico (adimensional);

IDT $>0,108=$ hipermétrico;

$0,105<$ IDT $=0,108$ : eumétrico;

IDT $<0,105$ = hipométrico;

- Índice de conformação = (perímetro torácico) ${ }^{2} /$ altura na cernelha (adimensional);

Valor de 2,1125 é ideal para o cavalo tipo sela;

- Índice de carga $1=\left((\text { perímetro torácico })^{2}\right.$ x 56)

/altura na cernelha $(\mathrm{kg})$;

- Índice de carga $2=\left((\text { perímetro torácico })^{2} \times 95\right)$ /altura na cernelha $(\mathrm{kg})$;

Os dados coletados durante as entrevistas foram submetidos às análises estatísticas descritivas, utilizando o software estatístico GraphPad Instat (versão 3.06). Baseado nas respostas dos entrevistados sobre a raça dos animais, esses foram separados em dois grupos: mestiços e sem raça definida. De acordo com os relatos e descrições feitos pelos proprietários dos animais, os equinos sem raça definida descendiam dos animais adaptados ao bioma Caatinga, sem infusão de raças exóticas. Já os mestiços resultavam do cruzamento entre os animais sem raça definida e equinos Quarto de Milha. Na sequência, os resultados das medidas lineares e índices morfométricos foram utilizados para comparar os dois grupos raciais, através do delineamento experimental inteiramente ao acaso composto por dois tratamentos: mestiços e sem raça definida.

Os resultados das medidas de altura na garupa, dorso e costado; vazio subesternal; comprimentos da cabeça, dorso-lombo e corpo; largura da cabeça; perímetro da canela; proporção costado/vazio subesternal e índice dáctilo-torácico não apresentaram distribuição normal, sendo submetidos ao teste não paramétrico de Mann Whitney, a 5\% de probabilidade do erro, utilizando o software estatístico GraphPad Instat (versão 3.06). Já as demais medidas e índices apresentaram distribuição normal, sendo submetidos à análise de variância e as médias comparadas pelo teste de Fisher, a 5\% de probabilidade do erro, utilizando o software estatístico SISVAR (versão 5.60).

\section{Resultados e Discussão}

Em relação ao sexo dos equinos participantes de Pegas de Boi no Mato, observouse predomínio de machos castrados nas disputas (78 animais), tendo sido contabilizado apenas 19 garanhões e cinco fêmeas. Maior frequência de machos castrados nessas disputas reforça a observação feita por Melo et al. (2013) de que a castração da maioria dos machos é um dos fatores que contribuem para a quase extinção da raça Nordestina, ao impossibilitar os acasalamentos e o fluxo gênico dentro do rebanho.

A opção pela castração está associada, dentre outros fatores, a maior docilidade dos animais castrados, desejável tanto para práticas esportivas quanto para a lida diária no campo. Já o pequeno número de garanhões pode estar relacionado a seleção rigorosa feita pelos criadores que priorizam para reprodução somente os indivíduos com melhor conformação e desempenho, que na fala do sertanejo são usados para "tirar a raça". Outra hipótese que também justificaria a menor frequência de garanhões nas disputas seria a preferência dos proprietários em usar garanhões de outras raças, corroborando a 
informação de Costa et al. (2001) de que as fêmeas da raça Nordestina vêm sendo utilizadas com reprodutores das raças Mangalarga Marchador e Quarto de Milha, para produção de mestiços destinados à exploração em Vaquejadas.

Participação ainda menor de fêmeas nas Pegas de Boi provavelmente deve-se a impossibilidade de usá-las durante todo o ano, já que precisam ser poupadas durante parte do período gestacional, especialmente nas Pegas de Boi onde o risco de acidentes é alto.

Observou-se nos animais mensurados maior frequência das pelagens alazã $(32,6 \%)$, tordilha $(27,4 \%)$ e castanha $(22,1 \%)$, sendo menos frequentes as pelagens alazã sobre baia $(5,3 \%)$, baia $(3,2 \%)$, preta $(3,2 \%)$, apalusa $(2,1 \%)$, pampa $(2,1 \%)$, lobuna $(1,1 \%)$ e rosilha $(1,1 \%)$. Maior frequência da pelagem alazã pode estar relacionada a influência da raça Quarto de Milha no rebanho avaliado, pois enquanto na raça Nordestina havia predomínio das pelagens tordilha e castanha (Torres e Jardim, 1992; Melo et al., 2013), na raça Quarto de Milha a pelagem alazã é a mais comum (ABQM, 2019).

Já a frequência da pelagem tordilha, segunda mais prevalente no rebanho avaliado, pode estar associada a alguns fatores. Melo et al. (2013), observaram que a pelagem tordilha foi a mais frequente na raça Nordestina e atribuíram isso a preferência de alguns criadores e proprietários que consideravam os animais tordilhos mais resistentes e dispostos para a lida diária, promovendo preferencialmente acasalamentos de animais dessa pelagem. Essa ideia tem forte caráter popular e, por isso, empírico, já que não há indícios de que o gene da pelagem tordilha influencie o desempenho físico dos equinos.

Além da predileção dos criadores por cavalos tordilhos, o gene responsável por essa pelagem é epistático, ou seja, sempre que estiver presente no genótipo, vai se manifestar no fenótipo. Portanto, todo produto tordilho é fruto de um acasalamento em que pelo menos um dos pais é tordilho (Rezende e Costa, 2012). Assim, a utilização de reprodutores tordilhos tende a aumentar rapidamente a frequência dessa pelagem no rebanho.

Já a pelagem castanha, terceira mais frequente nos animais avaliados, é muito presente na maioria dos rebanhos equinos criados no Brasil, independente da raça. Nos cavalos Quarto de Milha, por exemplo, é a segunda pelagem mais comum (ABQM, 2019).
Em relação as faixas etárias dos equinos, $13,4 \%$ dos indivíduos avaliados eram potros (entre dois e quatro anos). Embora a indicação seja montar os equinos somente após os 36 meses de vida, nessa espécie o desenvolvimento corporal cessa próximo aos cinco anos (Fontes, 1954; Nascimento, 1999). Assim, a participação de indivíduos com menos de cinco anos em competições deve ser vista com cautela. Considerando que na maioria das modalidades equestres os potros são iniciados no processo de doma entre dois e três anos, poucos animais encontram-se prontos para as disputas antes dos quatro anos. Além disso, a Pega de Boi no Mato exige muita agilidade e força física para perseguir e capturar o bovino solto na Caatinga, o que, por sua vez, demandando estruturas óssea, tendínea e muscular bem desenvolvidas, dificilmente observadas nos indivíduos ainda jovens.

Já os indivíduos adultos entre 5 e 10 anos compreenderam $60,7 \%$ dos animais avaliados. Provavelmente, isso está relacionado a melhor condição técnica e física dos cavalos dessa faixa etária, o que é traduzido em maior agilidade, destreza, força e resistência para perseguir os bovinos.

Observou-se menor frequência de equinos competidores acima dos 11 anos $(25,8 \%)$. Diferente de outras modalidades hípicas, como o Adestramento, onde os cavalos alcançam o desempenho máximo após os 10 anos de idade, nas Pegas de Boi no Mato a alta incidência de injúrias causadas pelos obstáculos naturais da Caatinga reduzem a vida útil dos animais.

Quanto as funções exercidas pelos equinos, para 73,5\% deles a Pega de Boi no Mato era apenas uma das atividades em que eram empregados. Além das disputas na Caatinga, os cavalos também eram utilizados nas atividades de rotina do campo e no transporte de pessoas, seja para deslocamento entre zonas rurais e urbanas ou para lazer (cavalgadas). Equinos criados somente para participarem de Pegas de Boi corresponderam a apenas $2 \%$ do total de animais avaliados.

Esse resultado deve-se a condição do homem do campo que geralmente não dispõe de um equino para cada atividade, sendo o mesmo cavalo empregado em todas as atividades que exigem trabalho animal. Nos sertões, isso é intensificado pela escassez de chuva e, consequentemente, de pasto que limitam o tamanho do rebanho. Além disso, muitos vaqueiros atuam como prestadores de serviço em fazendas de 
gado da região, sendo as Pegas de Boi no Mato apenas uma distração/lazer aos finais de semana.

Houve diferença entre os equinos mestiços e sem raça definida nas medidas lineares de alturas na cernelha $(\mathrm{p}=0,0104)$, dorso $(\mathrm{p}<0,01)$ e garupa $(\mathrm{p}=0,0017)$, sendo os mestiços 2,$0 ; 7,0$ e $3,0 \mathrm{~cm}$ mais altos que os animais sem raça definida, respectivamente (Tabela 1$)$.

Tabela 1. Medidas lineares, em metros (m), dos equinos sem raça definida (SRD) e mestiços participantes de Pega de Boi no Mato, com os respectivos valores de significância (Valor P), e medidas lineares reportadas para o remanescente da raça Nordestina e a raça Quarto de Milha

\begin{tabular}{lccccc}
\hline Medidas Lineares & $\begin{array}{c}\text { SRD } \\
(\mathrm{n}=55)\end{array}$ & $\begin{array}{c}\text { Mestiço } \\
(\mathrm{n}=47)\end{array}$ & Valor P & $\begin{array}{c}\text { Cavalo } \\
\text { Nordestino }^{1}\end{array}$ & $\begin{array}{c}\text { Quarto de } \\
\text { Milha }^{2}\end{array}$ \\
\hline Altura cernelha & $1,42^{\mathrm{b}}$ & $1,44^{\mathrm{a}}$ & 0,0104 & 1,33 & 1,50 \\
Altura dorso & $1,35^{\mathrm{B}}$ & $1,42^{\mathrm{A}}$ & $<0,01$ & 1,28 & 1,42 \\
Altura garupa & $1,41^{\mathrm{B}}$ & $1,44^{\mathrm{A}}$ & 0,0017 & 1,33 & 1,50 \\
Comp. cabeça & 0,59 & 0,60 & 0,4080 & 0,54 & 0,58 \\
Comp. pescoço & $0,65^{\mathrm{b}}$ & $0,67^{\mathrm{a}}$ & 0,0253 & 0,51 & 0,61 \\
Comp. espádua & 0,52 & 0,52 & 0,9589 & 0,44 & 0,53 \\
Comp. dorso-lombo & 0,54 & 0,54 & 0,2924 & 0,50 & 0,54 \\
Comp. garupa & 0,47 & 0,48 & 0,0933 & 0,43 & 0,51 \\
Comp. corpo & $1,40^{\mathrm{1}}$ & $1,43^{\mathrm{A}}$ & 0,0024 & 1,34 & 1,57 \\
Largura cabeça & 0,22 & 0,22 & 0,1450 & 0,19 & 0,20 \\
Largura peito & $0,38^{\mathrm{b}}$ & $0,40^{\mathrm{a}}$ & 0,0080 & 0,32 & 0,40 \\
Largura garupa & $0,49^{\mathrm{b}}$ & $0,50^{\mathrm{a}}$ & 0,0024 & 0,43 & 0,52 \\
Perímetro torácico & $1,61^{\mathrm{b}}$ & $1,64^{\mathrm{a}}$ & 0,0091 & 1,54 & 1,78 \\
Perímetro canela & 0,19 & 0,19 & 0,9225 & 0,17 & 0,20 \\
Altura costado & $0,61^{\mathrm{B}}$ & $0,63^{\mathrm{A}}$ & 0,0032 & 0,58 & 0,62 \\
\hline
\end{tabular}

Letras maiúsculas distintas indicam diferença entre Mestiços e SRD pelo teste de Mann-Whitney $(\mathrm{p}<0,05)$.

Letras minúsculas distintas indicam diferença entre Mestiços e SRD pelo teste Fisher $(\mathrm{p}<0,05)$.

${ }^{1}$ Melo et al. (2013)

${ }^{2}$ Torres et al. (2020)

Considerando que os equinos Quarto de Milha competidores de Vaquejada em Pernambuco apresentam alturas médias na cernelha e garupa de $1,50 \mathrm{~m}$ e no dorso de $1,42 \mathrm{~m}$ (Torres et al., 2020), faz sentido no presente estudo os mestiços serem mais altos que os cavalos sem raça definida. Para demonstrar a forte influência da raça Quarto de Milha de Vaquejada nos plantéis do Nordeste brasileiro, de acordo com Lima et al. (2016), o rebanho de equinos destinados à vaquejada, predominantemente Quarto de Milha, já é o terceiro maior do país, representando $12,9 \%$ do rebanho equino nacional destinado aos esportes.

Os equinos sem raça definida foram 9,$0 ; 8,0$ e 7,0 cm mais altos na cernelha, dorso e garupa, que os remanescentes da raça Nordestina (Melo et al., 2013). Isso é indício de que mesmo os cavalos sem raça definida, usados atualmente em Pegas de Boi no Mato, também são mestiços. Além disso, melhores condições de manejo alimentar e sanitário ofertadas a esses animais, devido aos avanços da equinocultura e, principalmente, maior acesso dos vaqueiros às informações técnicas, podem contribuir para maior desenvolvimento físico dos animais.

Não houve diferença entre os equinos mestiços e sem raça definida nas medidas lineares de comprimentos da cabeça $(\mathrm{p}=0,4080)$, espádua $(\mathrm{p}=0,9589)$, dorso-lombo $(\mathrm{p}=0,2924)$ e garupa $(\mathrm{p}=0,0933)$. Já as medidas de comprimentos do pescoço e corpo dos equinos mestiços foram $2,0 \mathrm{e}$ $3,0 \mathrm{~cm}$ maior que dos animais sem raça definida, respectivamente. Maior comprimento corporal dos mestiços em relação aos cavalos sem raça definida era esperado, pois as medidas de alturas na cernelha, dorso e garupa também foram superiores nos animais com sangue Quarto de Milha.

As medidas de comprimentos de cabeça e pescoço dos mestiços e cavalos sem raça definida foram superiores as da raça Nordestina e Quarto Milha, indicando que os animais utilizados 
atualmente em Pegas de Boi no Mato têm um conjunto de frente (cabeça e pescoço) mais pesado.

Os equinos mestiços e sem raça definida apresentaram mesma largura de cabeça $(0,22 \mathrm{~m})$. Já as larguras no peito e garupa dos cavalos mestiços foram, respectivamente, 2,0 e $1,0 \mathrm{~cm}$ maiores que dos animais sem raça definida. Quando comparado ao remanescente da raça Nordestina (Melo et al., 2013) e aos equinos Quarto de Milha de Vaquejada (Torres et al., 2020), a largura de garupa dos mestiços foi mais próxima a dos cavalos Quarto de Milha e a largura peito foi a mesma entre eles $(0,40$ $\mathrm{m})$. Como o grande desenvolvimento muscular e amplitude de peito e garupa são características marcantes dos exemplares Quarto de Milha, a semelhança na largura do peito entre mestiços e cavalos Quarto de Milha novamente reforça a influência dessa raça nos atuais rebanhos nordestinos de Pega de Boi no Mato.

Se por um lado maiores dimensões corporais dos equinos de Pega de Boi no Mato podem conferir maior força física a esses animais; durante a perseguição dos bovinos pela Caatinga cavalos com maior massa corporal estarão mais susceptíveis aos obstáculos naturais desse bioma, sendo acometidos por acidentes em maior número e gravidade. Assim, optar em seguir o modismo das Vaquejadas, que buscam equinos cada vez maiores para perseguir e derrubar bovinos pesados, em terrenos cobertos por camada de $40 \mathrm{~cm}$ de areia, pode resultar em maior sofrimento e menor vida útil dos cavalos mestiços usados nas Pegas de Boi no Mato.

Além de maior riscos aos animais, o distanciamento dos equinos de Pega de Boi com o cavalo do ecotipo Nordestino também pode causar perda de desempenho na Caatinga, onde essa raça já prestou relevantes serviços à economia da região, não só no transporte de carga, mas também no transporte do homem, vencendo longas estradas e veredas sinuosas, por terrenos sempre ásperos, onde pisou firme e aprumado, sobre cascos rígidos e pequenos, desprovidos de ferraduras, regularmente adaptados à dureza da terra (Costa et al., 1974). Sem o cavalo Nordestino, o vaqueiro não poderia trabalhar com tanta eficiência, pois muitas raças não possuem cascos fortes para suportar o trabalho nesta região (Melo et al., 2013).

Não houve diferença $(p=0,9225)$ entre $o$ perímetro da canela dos mestiços e cavalos sem raça definida, tendo ambos os grupos apresentando valor médio de $0,19 \mathrm{~m}$. O perímetro de canela está diretamente relacionado a qualidade óssea e tendínea dos animais, ou seja, quando maior a circunferência da canela mais fortes serão as estruturas de sustentação do corpo. Nesse sentido, a semelhança no valor do perímetro da canela dos cavalos de ambos os grupos raciais indica que maiores dimensões corporais dos mestiços (alturas, comprimentos e larguras) não estão sendo acompanhadas por aumento proporcional da ossatura, essencial para suportar o maior peso corporal, principalmente durante as disputas. Isso pode deixar os animais mais susceptíveis às lesões ortopédicas, devido a ossatura e/ou tendões mais frágeis.

Embora os mestiços tenham apresentado altura do costado e vazio subesternal 2,0 e $1,0 \mathrm{~cm}$ maiores que os animais sem raça definida, a proporção entre essas duas medidas foi semelhante nos dois grupos, com os mestiços apresentando relação entre altura do costado e vazio subesternal de 0,84 ou 1,0:1,19 e os cavalos sem raça definida de 0,82 ou 1,0:1,21 (Tabela 2). De acordo com Fontes (1954), a relação entre altura do costado e vazio subesternal de equinos do tipo físico tração é de 1,0:1,0; para cavalos do tipo sela para trabalho é de 1,0:1,2 e para os animais de sela para esporte é de 1,0:1,5. Nesse sentido, as proporções entre essas duas medidas para ambos os grupos raciais estão mais próximas do tipo físico sela para trabalho, justamente a função em que são empregados, já que 73,5\% deles além das Pegas de Boi também são empregados na lida do campo.

Os equinos Mestiços apresentaram maior peso calculado que os cavalos sem raça definida, 360,2 e $334,0 \mathrm{~kg}$, respectivamente. Considerando que medidas de comprimento, profundidade e largura dão noção do volume corporal dos animais de produção, ou seja, do espaço que esses ocupam, era esperando que os mestiços apresentassem maior peso corporal, já que foram maiores no comprimento do corpo, no vazio subesternal (profundidade) e na largura do peito que os animais sem raça definida.

Não houve diferença $(\mathrm{p}=0,1141)$ entre mestiços e cavalos sem raça definida no índice dáctilo-torácico, com valores de 0,1135 e 0,1153, respectivamente. $\mathrm{O}$ índice dáctilo-torácico é a relação entre as medidas de perímetro torácico e de canela, resultando nas seguintes classificações: hipermétricos (>0,108); eumétricos $(0,105>$ 0,108); hipométricos $(<0,105)$ (Ribeiro, 1989; Torres e Jardim, 1992). Como a hipométria é indesejável para a maioria das raças equinas, por indicar ossatura e/ou tendões mais frágeis e, 
consequentemente, maior susceptibilidade às lesões ortopédicas, os valores observados no presente estudo favorecem tanto os mestiços quanto os animais sem raça definida, pois ambos se enquadraram como hipermétricos.

Tabela 2. Índices morfométricos dos equinos sem raça definida (SRD) e mestiços participantes de Pega de Boi no Mato, com os respectivos valores de significância (Valor P), e índices morfométricos reportados para o remanescente da raça Nordestina e a raça Quarto de Milha

\begin{tabular}{lccccc}
\hline Índices morfométricos & $\begin{array}{c}\text { SRD } \\
(\mathrm{n}=55)\end{array}$ & $\begin{array}{c}\text { Mestiço } \\
(\mathrm{n}=47)\end{array}$ & Valor P & $\begin{array}{c}\text { Cavalo } \\
\text { Nordestino }^{1}\end{array}$ & $\begin{array}{c}\text { Quarto de } \\
\text { Milha }^{2}\end{array}$ \\
\hline Vazio subesternal & $0,74^{\mathrm{B}}$ & $0,75^{\mathrm{A}}$ & 0,0487 & 0,75 & 0,81 \\
Proporção costado/vazio & 0,82 & 0,84 & 0,9920 & 0,77 & 0,77 \\
Peso calculado $(\mathrm{kg})$ & $334,0^{\mathrm{b}}$ & $360,2^{\mathrm{a}}$ & 0,0055 & 292,07 & 449,4 \\
Índice dáctilo-torácico & 0,1153 & 0,1135 & 0,1141 & 0,113 & 0,1093 \\
Índice de conformação & $1,82^{\mathrm{b}}$ & $1,88^{\mathrm{a}}$ & 0,0200 & 1,78 & 2,11 \\
Índice de carga 1 $(\mathrm{kg})$ & $102,1^{\mathrm{b}}$ & $105,5^{\mathrm{a}}$ & 0,0200 & 99,2 & 118,13 \\
Índice de carga 2 $(\mathrm{kg})$ & $173,2^{\mathrm{b}}$ & $179,0^{\mathrm{a}}$ & 0,0200 & 168,3 & 200,6 \\
\hline
\end{tabular}

Letras maiúsculas distintas indicam diferença entre Mestiços e SRD pelo teste de Mann-Whitney $(\mathrm{p}<0,05)$.

Letras minúsculas distintas indicam diferença entre Mestiços e SRD pelo teste Fisher $(p<0,05)$.

${ }^{1}$ Melo et al. (2013)

${ }^{2}$ Torres et al. (2020)

Embora os mestiços tenham apresentado maior valor para o índice de conformação que os cavalos sem raça definida, 1,88 e 1,82, respectivamente, ambos apresentaram valor abaixo de 2,1125, considerado ideal para o cavalo tipo sela.

Observou-se que os equinos mestiços suportam maior peso sobre o dorso, seja a passo (índice de carga 1) ou ao trote (índice de carga 2) que os animais sem raça definida. Esse resultado é condizente com as maiores dimensões corporais dos mestiços, que possibilitam a eles suportar maior peso sobre o dorso em ambos os andamentos.

\section{Conclusão}

Nas Pegas de Boi no Mato há predomínio de equinos machos castrados, na faixa etária entre $5 \mathrm{e}$ 10 anos, de pelagens alazã, tordilha e castanha, cujas funções vão além das participações nas disputas. Esses equinos são agrupados como indivíduos sem origem definida ou mestiços, sendo que ambos os grupos raciais possuem medidas e proporções corporais intermediárias entre $\mathrm{O}$ remanescente da raça Nordestina e cavalos Quarto de Milha de Vaquejada.

\section{Conflito de interesse}

Os autores declaram não existir conflito de interesses.

\section{Comitê de Ética}

Este estudo foi aprovado pela Comissão de Ética no Uso de Animais da Universidade Federal Rural de Pernambuco, licença ${ }^{\circ}$ 053/2016.

\section{Agradecimentos}

Agradecemos a Universidade Federal Rural de Pernambuco pelos recursos disponibilizados para realização do estudo.

\section{Referências}

ABQM. Associação Brasileira de Criadores de Quarto de Milha. Pelagens oficiais. Disponível em:

<https://www.abqm.com.br/pt/conteudos/quart o-de-milha/pelagens-oficiais >. Acesso em: 19 nov. 2019.

Cavalus. A 'Pega de Boi' é uma tradição nordestina muito importante. Disponível em: $<$ https://cavalus.com.br/geral/a-pega-de-boi-euma-tradicao-nordestina-muito-importante>.

Acesso em: 10 set. 2018.

CCCCN. Comissão Coordenadora da Criação do Cavalo Nacional. Raça homenageada Pantaneira. Brasília: Ministério da Agricultura, 1983.

Costa, N.; Val, L.J.; Leite, G.U. Estudo da preservação do cavalo Nordestino. Recife: Departamento de Produção Animal, 1974. $169 \mathrm{p}$.

Costa, H.E.; Manso Filho, H.; Ferreira, L. Exterior e treinamento do cavalo. Recife: Imprensa Universitária, 2001. 169p. 
Fontes, L.R. Exterior, raças e julgamento dos animais domésticos. Belo Horizonte: Universidade Rural do Estado de Minas Gerais, 1954. 126p.

Lima, R.A.S.; Shirota, R.; Cintra, A.G. Revisão do Estudo do Complexo do Agronegócio do Cavalo. Brasília: MAPA, 2016. 54p.

Melo, J.B.; Pires, D.A.F.; Ribeiro, M.N. Perfil fenotípico do remanescente do cavalo nordestino no nordeste do Brasil. Archivos de Zootecnia, 62(238): 171-180, 2013.

Menezes, S.S.M.; Almeida, M.G. Vaquejada: a pega de boi na Caatinga resiste no sertão sergipano. Revista Vivência, 34(1): 181-193, 2008.

Nascimento, J.F. Mangalarga marchador: tratado morfofuncional. Belo Horizonte: ABCCMM, 1999. 577p.

Oom, M.M.; Ferreira, J.C. Estudo biométrico do cavalo Alter. Revista Portuguesa de Ciências Veterinárias, 82(482): 101-148, 1987.
Pereira, R.M. Dominação e confiança: vaqueiros e animais nas pegas de boi do sertão de Pernambuco. Teoria e Cultura, 11(2): 63-80, 2016.

Rezende, A.S.C.; Costa, M.D. Pelagem dos equinos: nomenclatura e genética. Belo Horizonte: FEP-MVZ, 2012. 111p.

Ribeiro, D.B. O cavalo: raças, qualidades e defeitos. $2^{\text {a }}$ ed. São Paulo: Globo, 1989. 318p.

Santiago, J.M.; Rezende, A.S.C.; Lana, A.M.Q.; Fonseca, M.G.; Lage, J. Evolução das medidas morfométricas da raça Mangalarga Marchador. Revista Caatinga, 29(1): 191-199, 2016.

Torres, A.D.P.; Jardim, W.R. Criação do cavalo e de outros equinos. $3^{\text {a }}$ ed. São Paulo: Editora Nobel, 1992. 654p.

Torres, P.B.; Santiago, J.M.; Lucena, J.E.C.; Lima, G.S.; Melo, D.A.S.; Moraes, A.V.M.; Silva, A.C.; Bezerra, D.G.N. Bioscience Journal, 36(6): 2133-2141, 2020. 